\title{
Age-Dependent Impact of Pre-Transplant Intensive Care Unit Stay on Mortality in Heart Transplant Recipients
}

\author{
Trent Simsa, b, c, g, Dmitry Tumin ${ }^{\mathrm{a}}$, Don Hayes, Jr. ${ }^{\text {c, d, e }}$, \\ Joseph D. Tobias ${ }^{a, b, c, f}$
}

\begin{abstract}
Background: Heart transplantation (HTx) is a treatment option for refractory end-stage heart failure. Severe illness requiring pre-transplant intensive care unit (ICU) stay may be a risk factor for diminished posttransplant survival, but this association is surprisingly inconsistent in recent studies. To clarify the significance of ICU stay as a risk factor for heart transplant outcomes, we aimed to define if patient age was a factor in which ICU stay was predictive of survival after HTx.
\end{abstract}

Methods: De-identified data were obtained on isolated first-time HTx performed during the years 2006 - 2015 from the UNOS Registry. Nine age groups were defined. The primary outcome was 1-year posttransplant mortality. Cox proportional hazard regression estimated unadjusted and adjusted hazard ratio (HR) associated with pre-transplant ICU stay in each age group.

Results: The analysis included 19,508 patients (9\% deceased within 1 year). In the overall cohort, pre-transplant ICU stay was associated with increased hazard of 1 -year mortality $(\mathrm{HR}=1.3 ; 95 \%$ confidence interval $(\mathrm{CI}): 1.2-1.4 ; \mathrm{P}<0.001)$; but further univariate analysis showed a greater hazard of 1-year mortality associated with ICU stay in infants $(\mathrm{HR}=2.2 ; 95 \% \mathrm{CI}: 1.5-3.2 ; \mathrm{P}<0.001)$. However, the adjusted analysis found that adults ages 40 - 49 had the highest statistically significant hazard of 1 -year mortality $(\mathrm{HR}=1.5 ; 95 \% \mathrm{CI}: 1.1-2.1 ; \mathrm{P}=0.011)$.

Conclusions: Our study established age variation in the association between ICU stay and survival after HTx, with this association being

Manuscript submitted April 19, 2019, accepted May 30, 2019

aDepartment of Anesthesiology and Pain Medicine, Nationwide Children's Hospital, Columbus, OH, USA

bDepartment of Pediatric Critical Care Medicine, Nationwide Children's Hospital, Columbus, OH, USA

${ }^{\mathrm{c}}$ Department of Pediatrics, The Ohio State University College of Medicine, Columbus, OH, USA

dDepartment of Pulmonary Medicine, Nationwide Children's Hospital, Columbus, OH, USA

eDepartment of Pulmonary Medicine, The Ohio State University College of Medicine, Columbus, OH, USA

fDepartment of Anesthesiology and Pain Medicine, The Ohio State University College of Medicine, Columbus, OH, USA

gCorresponding Author: Trent Sims, Department of Pediatric Critical Care Medicine, Nationwide Children's Hospital, 700 Children's Drive, Columbus, OH 43205, USA. Email: trent.sims@nationwidechildrens.org

doi: https://doi.org/10.14740/cr870 strongest among adults, 40 to 49 years of age, undergoing HTx. Previous data suggesting decreased survival in infants may be related to the increased use of extracorporeal membrane oxygenation as a mechanical cardiac assist rather than ventricular assist devices.

Keywords: Heart transplant; Cardiology; Intensive care medicine; Transplantation

\section{Introduction}

Heart transplantation is the definitive treatment for patients with end-stage heart failure that is refractory to optimal medical management $[1,2]$. Survival following heart transplantation is quite favorable with median survival ranging from 8.3 to 20.7 years among all age groups [3, 4]. Survival is affected by severity of illness prior to transplantation, underlying diagnosis, and availability of donor hearts [5]. There are many known pre-transplant risk factors for decreased survival following heart transplant (HTx), including the need for mechanical circulatory support, use of mechanical ventilation, and associated renal dysfunction $[1,5,6]$. Although pre-transplant severity of illness is a known risk factor, it is unclear whether admission to the intensive care unit (ICU) prior to transplant impacts post-transplant survival. Studies to date show significant variability in whether or not pre-transplant ICU stay reduces survival after HTx [2, 6-8]. Furthermore, some studies even argue that pre-transplant ICU stay may improve posttransplant outcomes by optimizing clinical condition while patients are on the waiting list [1].

The aim of our study is to determine if age of the HTx recipient is influencing outcomes in patients requiring ICU stay. Prior studies suggest that age is a significant moderator for survival after HTx. Pre-transplant ICU stay has been associated with decreased post-transplant survival in infants and older adults. However, this association does not appear to be present in older children or middle-aged adults [1, 6, 9-11]. We hypothesized that ICU stay would be associated with decreased survival in patients at the two extremes of ages (infants and adults $\geq 70$ years of age).

\section{Materials and Methods}

Analysis of the United Network of Organ Sharing (UNOS) 
Registry was approved by the Nationwide Children's Hospital Institutional Review Board with a waiver of individual consent. This study was conducted in compliance with all the applicable institutional ethical guidelines for the care, welfare and use of animals. These data were used to identify patients of all ages who received first-time HTx between January, 2006 and June, 2015. Patients were excluded from the study if they were undergoing repeat transplantation or if they underwent simultaneous multiple organ transplantation. Multivariable analysis excluded patients missing data on covariates, described below. Patients were arbitrarily divided into nine age groups ( $\leq$ 1, 2 - 11, 12 - 18, 19 - 29, 30 - 39, 40 - 49, 50 - 59, 60 - 69, and $\geq 70$ years). The primary outcome was 1 -year post-transplant mortality, with a secondary outcome of overall post-transplant mortality during the study period. Patients were followed up through December 2016.

Mortality outcomes were analyzed using Cox proportional hazard regression, which estimated the hazard ratio (HR), associated with pre-transplant ICU stay in each age group. The interaction between ICU stay and age group determined whether the HR associated with ICU stay was significantly modified for older or younger recipients, as compared to the reference group of 40 - 49 years old patients. Multivariable adjustment of the Cox model included gender, race, body mass index (BMI), indication for transplant, mechanical circulatory support, mechanical ventilation, renal dialysis, inotropes, bilirubin, pretransplant infection, and graft ischemic time. BMI categories included underweight, normal weight, and overweight; and were defined using age-sex-specific percentiles for ages 0 - 18 and standard BMI cutoffs for ages 19 and older. Analyses were performed in Stata/IC 14.2 (College Station, TX: Stata-Corp $\mathrm{LP}$ ), and $\mathrm{P}<0.05$ was considered statistically significant.

\section{Results}

There were 19,508 patients meeting inclusion criteria, of whom 18,396 had complete data on study covariates. Median follow-up was 4 years, with a total of 4,688 recorded deaths, of which 1,928 occurred within the first year post-transplant. Prior to transplantation, 6,309 (32\%) of patients were in the ICU, and the characteristics of these patients are compared to patients not in the ICU at the time of transplant using Chisquare tests in Table 1.

On unadjusted analysis of 1-year mortality, pre-transplant ICU stay was associated with significant increases in mortality hazard for ages $<1$ y $(\mathrm{HR}=2.1 ; 95 \%$ confidence intervals (CI): 1.4, 3.1; $\mathrm{P}<0.001), 2$ - 11 years $(\mathrm{HR}=1.7 ; 95 \% \mathrm{CI}: 1.0$, 2.8; $\mathrm{P}=0.048), 40-49$ years $(\mathrm{HR}=1.6 ; 95 \% \mathrm{CI}: 1.3,2.2 ; \mathrm{P}$ $<0.001)$, and $50-59$ years $(\mathrm{HR}=1.4 ; 95 \% \mathrm{CI}: 1.1,1.6 ; \mathrm{P}=$ 0.002) (Fig. 1). After multivariable adjustment (Table 2), the association of ICU stay with transplant mortality was strongly attenuated for infants and young children, and remained statistically significant only in the $40-49$ years $(\mathrm{HR}=1.5 ; 95 \% \mathrm{CI}$ : $1.2,2.0 ; \mathrm{P}=0.003)$ and $50-59$ years groups $(\mathrm{HR}=1.4 ; 95 \%$ CI: $1.1,1.7 ; \mathrm{P}=0.001)$.

The analysis of overall mortality after transplant revealed weaker associations between ICU stay and this outcome (Fig.
2). On unadjusted Cox regression, ICU stay was associated with increased mortality hazard for infants age $<1$ year $(\mathrm{HR}=$ 1.6; 95\% CI: 1.2, 2.1; $\mathrm{P}=0.002)$, as well as adults ages 40 - 49 years $(\mathrm{HR}=1.3 ; 95 \% \mathrm{CI}: 1.1,1.5 ; \mathrm{P}=0.002)$. However, after multivariable adjustment (Table 3), pre-transplant ICU stay was statistically significantly associated with increased hazard of overall post-transplant mortality only among adults ages 40 - 49 years $(\mathrm{HR}=1.3 ; 95 \% \mathrm{CI}: 1.1,1.5 ; \mathrm{P}=0.007)$.

Multivariate predictors associated with increased risk of 1 year post-transplant mortality included non-Hispanic Black race/ethnicity $(\mathrm{HR}=1.4 ; 95 \% \mathrm{CI}: 1.2,1.5 ; \mathrm{P}<0.001)$, the need for mechanical ventilation ( $\mathrm{HR}=1.8 ; 95 \% \mathrm{CI}$ : $1.5,2.2$; $\mathrm{P}<0.001)$, use of both extracorporeal membrane oxygenation $(\mathrm{ECMO})(\mathrm{HR}=3.1 ; 95 \% \mathrm{CI}: 2.4,4.0 ; \mathrm{P}<0.001)$ and ventricular assist devices (VADs) $(\mathrm{HR}=1.4 ; 95 \% \mathrm{CI}: 1.2,1.6 ; \mathrm{P}<$ $0.001)$, dialysis while on the waitlist ( $\mathrm{HR}=2.2 ; 95 \% \mathrm{CI}: 1.8$, $2.8 ; \mathrm{P}<0.001$ ), infection requiring intravenous (IV) antibiotics while on the waitlist ( $\mathrm{HR}=1.2 ; 95 \% \mathrm{CI}: 1.1,1.4 ; \mathrm{P}=0.001)$, a bilirubin level $>2 \mathrm{mg} / \mathrm{dL}(\mathrm{HR}=1.6 ; 95 \%$ CI: $1.4,1.9 ; \mathrm{P}<$ $0.001)$, and an allograft ischemia time $>4 \mathrm{~h}(\mathrm{HR}=1.3 ; 95 \%$ CI: 1.1, 1.6; $\mathrm{P}=0.001)$. All indications for HTx were protective when compared to the reference group of congenital heart disease (Table 2).

Multivariate predictors associated with increased risk of overall post-transplant mortality included were similar to those of 1-year mortality including non-Hispanic Black race/ethnicity ( $\mathrm{HR}=1.5 ; 95 \% \mathrm{CI}: 1.4,1.6 ; \mathrm{P}<0.001$ ), overweight (HR $=1.2 ; 95 \%$ CI: $1.1,1.3 ; \mathrm{P}<0.001)$, mechanical ventilation $(\mathrm{HR}=1.3 ; 95 \% \mathrm{CI}: 1.1,1.5 ; \mathrm{P}=0.002)$, use of ECMO $(\mathrm{HR}=$ $2.0 ; 95 \%$ CI: 1.6, 2.5; $\mathrm{P}<0.001)$, dialysis while on the waitlist $(\mathrm{HR}=1.8 ; 95 \% \mathrm{CI}: 1.5,2.2 ; \mathrm{P}<0.001)$, infection requiring IV antibiotics on the waitlist ( $\mathrm{HR}=1.2 ; 95 \% \mathrm{CI}: 1.1,1.3$; P $=0.001)$, a bilirubin level $>2 \mathrm{mg} / \mathrm{dL}(\mathrm{HR}=1.2 ; 95 \%$ CI: 1.1 , $1.3 ; \mathrm{P}<0.001)$, and an allograft ischemia time $>4 \mathrm{~h}(\mathrm{HR}=$ 1.2; $95 \%$ CI: 1.1 1.4; P<0.001). All indications for HTx were protective when compared to our reference group (congenital heart disease) (Table 3).

\section{Discussion}

Our most important findings include pre-transplant ICU stay was associated with increased hazard of 1-year mortality and further univariate analysis showed a greater hazard of 1-year mortality associated with ICU stay in infants. However, the adjusted models determined that the 1-year mortality hazard was no longer significant; while adults aged 40 - 49 years remained to have a significantly increased 1-year mortality hazard. This increased risk of 1-year mortality as a function of pre-transplant ICU stay was independent of the increased risks associated with transplant indication, type of mechanical circulatory support, receipt of mechanical ventilation or renal dialysis, use of vasopressor/inotropes, presence of pre-transplant infection or graft ischemia time. Therefore, this is the first study to demonstrate an increased risk for early mortality in adults ranging in age from 40 to 49 years compared to other age groups.

Consideration of ICU status in the determination of eligibility of heart transplantation could inform decisions about 
Table 1. Patient Characteristics According to Pre-Transplant ICU Stay $(N=19,508)$

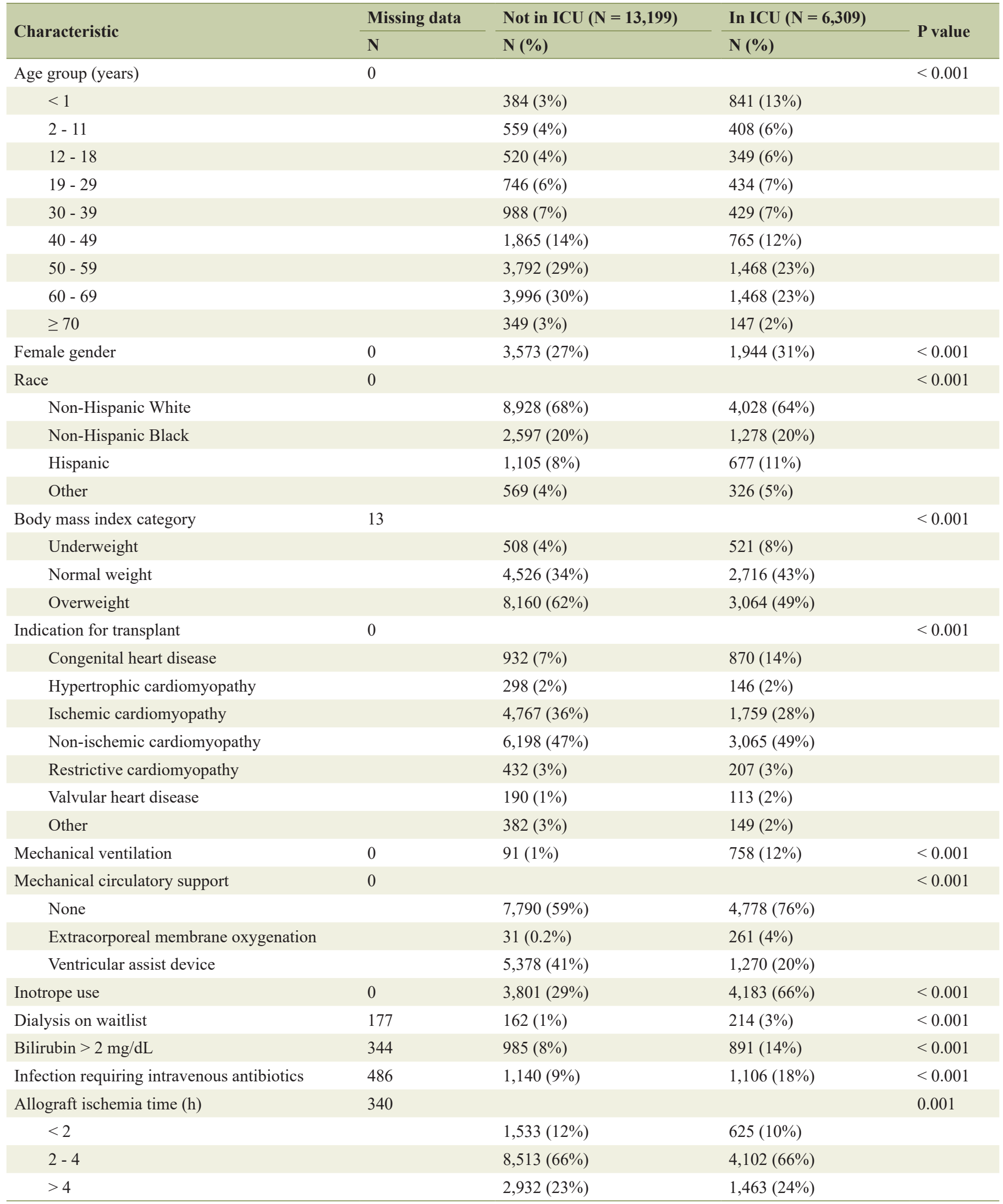




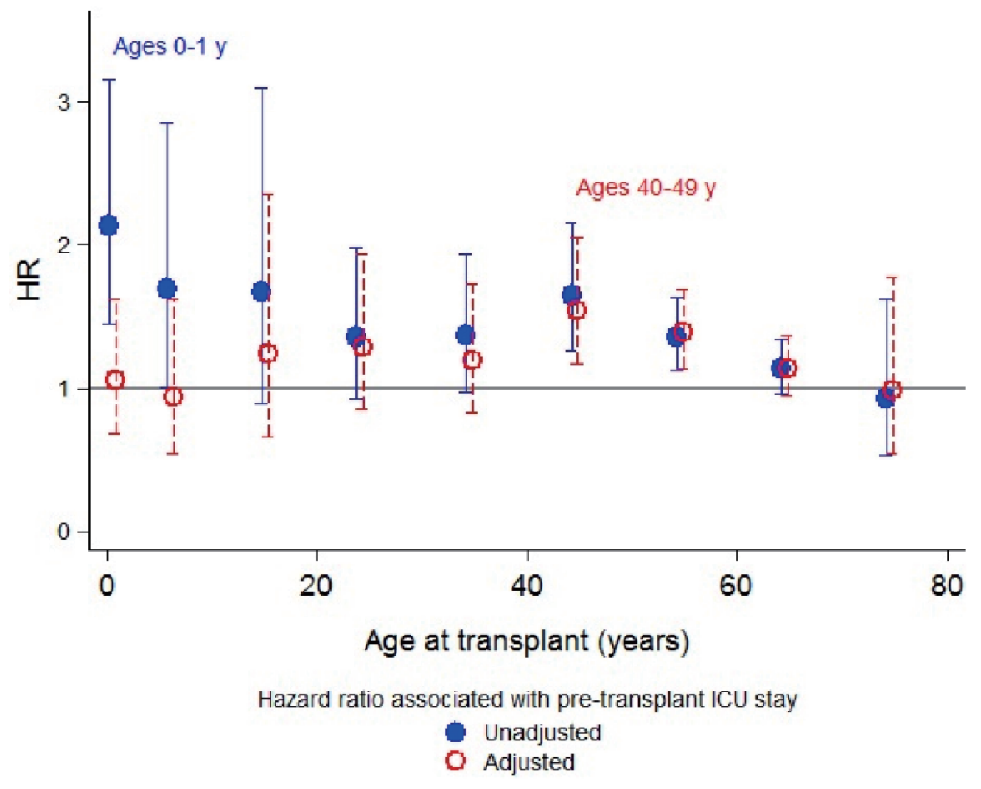

Figure 1. Age group-specific hazard ratios associated with pre-transplant intensive care unit stay for 1-year mortality, with $95 \%$ confidence intervals.

transplant waitlisting in patients who are at higher risk for decreased survival, and may even allow for more efficient allocation of donor hearts. One limitation of donor heart allocation is the prioritization based solely on medical urgency without consideration of the recipients' expected benefit or their risk for short-term complications, including mortality [1]. The result of this study demonstrates that ICU status in adults, specifically at the ages of 40 - 49 years, was associated with an increased risk of 1-year mortality compared to other groups. These results may be useful information to take into account during the allocation process and also when counseling patients and families.

The 1-year mortality of $9 \%$ in the current study was similar to other studies with 1-year mortality ranges of 7-9.9\% [1, $2,12]$. The role of ICU status prior to heart transplantation on post-transplant survival is unknown, as studies examining this have shown mixed results. Studies by Hsieh et al and Rana et al did not show a reduction in post-transplant survival in patients who were hospitalized in the ICU prior to transplantation $[2,8]$. This is in contrast to a study by Davies et al which showed a decreased 1-year survival in patients who were in ICU prior to transplantation [6]. It is important to note that all three of these studies were performed in only pediatric age groups and did not include adults.

In our adjusted analysis we used the type of mechanical cardiac support (MCS) as a covariate. Previous studies have clearly demonstrated that the use of ECMO for pre-transplant MCS is associated with decreased post-transplant survival compared to direct transplant of the use of VADs [1, 2, 4]. ECMO is also associated with a higher incidence of thromboembolic, hemorrhagic and infectious complications. As the smallest patients (neonates and infants) are unable to be supported with VADs due to lack of device availability, this puts this age group at a clear survival disadvantage compared to other age groups [1]. Therefore, patients transplanted during infancy include a higher proportion of patients supported with ECMO compared to other age groups where other types of MCS are feasible. We speculate that this is why the infant group had decreased survival in the univariate analysis, whereas, when use of MCS was controlled in our adjusted analysis, we did not see decreased survival in the infant group. It is also important to note that over the past decade the use of VADs for pre-transplant MCS has increased. This trend may account for the improving survival in post-transplant patients over this same time period $[2,13,14]$. Improvements in technology with ongoing developments may allow the use of VADs in smaller patients with a similar improvement in survival in the near future.

Although our study includes a large cohort of HTx recipients from multiple centers, it is important to note its limitations. Data were identified in a retrospective fashion through a national database that is susceptible to error in data entry. This database is also susceptible to variability in data entry between reporting centers as to which pre-transplant hemodynamic and clinical variables are reported. The analysis was also limited to variables collected by UNOS, and other potentially influential factors were not identified. Our data can support associations between variables and outcome; however, due to its retrospective nature, we are unable to determine causal relationships.

In summary, we present a large multicenter study examining the impact of pre-transplant ICU stay on survival after heart transplantation. As previous studies have demonstrated that the need for ECMO as a means of pre-transplant MCS is associated with decreased survival compared, in our adjusted analysis we used the type of MCS as a covariate, and no longer found decreased survival in infants. Our study is the first study to demonstrate an increased risk for early mortality in an adult age group (40 to 49 years) compared to other age groups. Con- 
Table 2. Multivariable Cox Proportional Hazards Analysis of 1-Year Mortality After Heart Transplantation $(\mathrm{N}=18,396)$

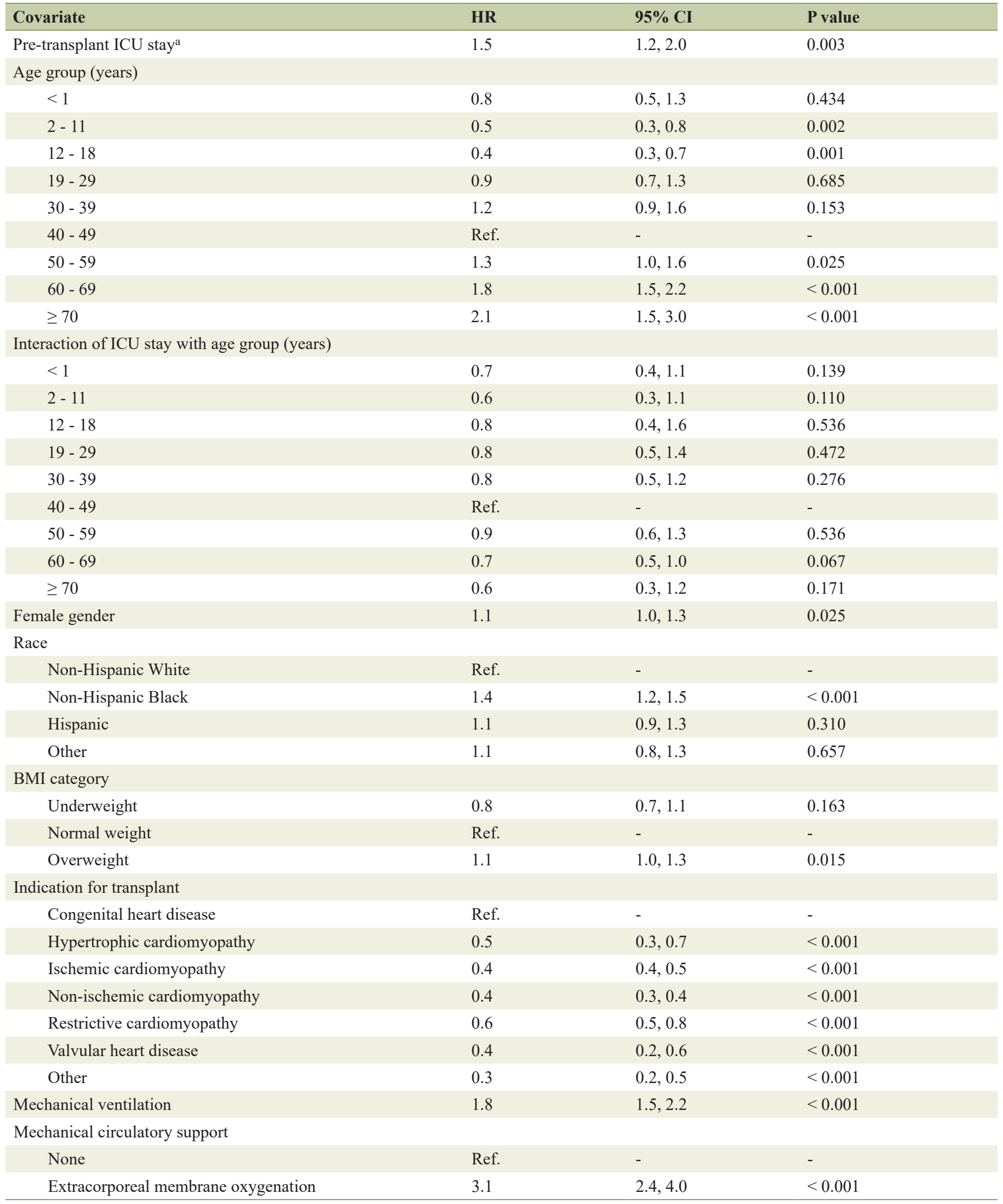


Table 2. Multivariable Cox Proportional Hazards Analysis of 1-Year Mortality After Heart Transplantation $(\mathrm{N}=18,396)-($ continued)

\begin{tabular}{|llll}
\hline Covariate & HR & 95\% CI & P value \\
\hline \multicolumn{1}{|c}{ Ventricular assist device } & 1.4 & $1.2,1.6$ & $<0.001$ \\
\hline Inotrope use & 1.0 & $0.9,1.1$ & 0.567 \\
Dialysis on waitlist & 2.2 & $1.8,2.8$ & $<0.001$ \\
Bilirubin $>2 \mathrm{mg} / \mathrm{dL}$ & 1.6 & $1.4,1.9$ & $<0.001$ \\
Infection requiring intravenous antibiotics & 1.2 & $1.1,1.4$ & 0.001 \\
Allograft ischemia time (h) & & - & - \\
$\quad<2$ & Ref. & 0.878 \\
$\quad 2-4$ & 1.0 & $0.8,1.2$ & 0.001 \\
\hline
\end{tabular}

aHazard ratio (HR) reflects estimate for ages 40 - 49 years. The interaction terms estimate how this HR is modified in other age groups. BMI: body mass index.

sideration of ICU status in determination of heart transplant eligibility may be indicated and may lead to more efficient allocation of donor hearts. Further research is needed to help delineate why adults, 40 - 49 years of age, have increased early mortality.

\section{Acknowledgments}

The authors have no conflict to disclose and no external sources of funding were used in this study. The data here have been supplied by the United Network of Organ Sharing as the contractor for the Organ Procurement and Transplantation Network. The interpretation and reporting of these data are the responsibility of the author(s) and in no way should be seen as an official policy of or interpretation by the OPTN or the US
Government.

\section{Financial Disclosure}

None to declare.

\section{Conflict of Interest}

None to declare.

\section{Informed Consent}

Not applicable.

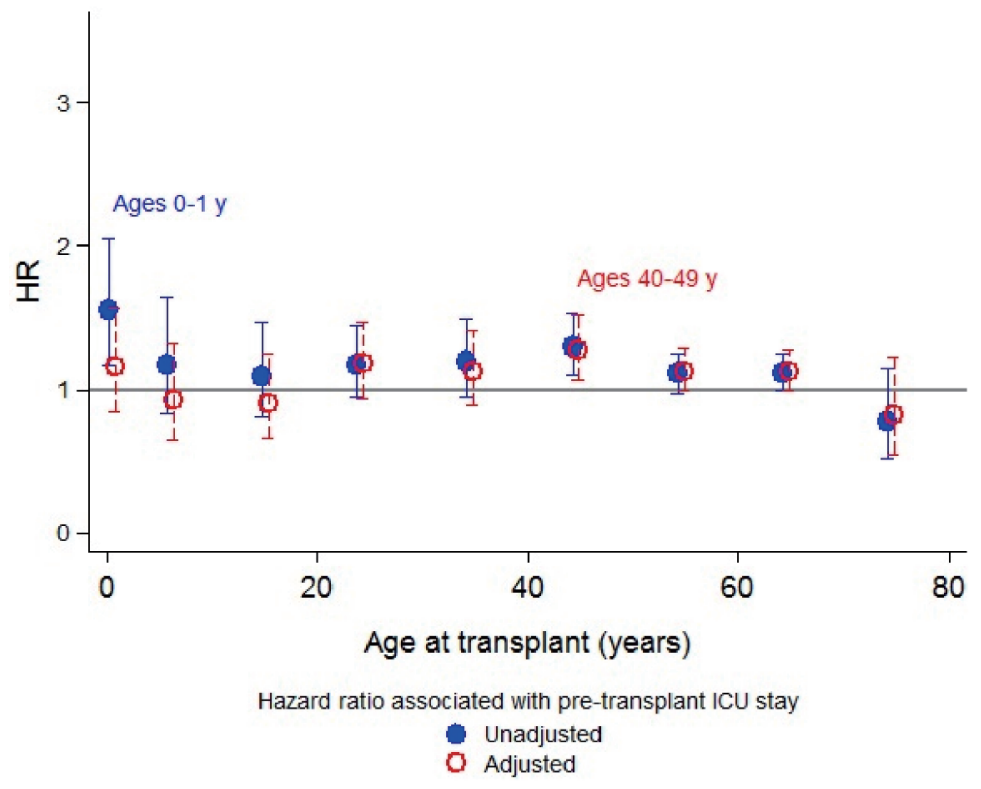

Figure 2. Age group-specific hazard ratios associated with pre-transplant intensive care unit stay for overall mortality, with $95 \%$ confidence intervals. 
Table 3. Multivariable Cox Proportional Hazards Analysis of Overall Mortality After Heart Transplantation $(\mathrm{N}=18,396)$

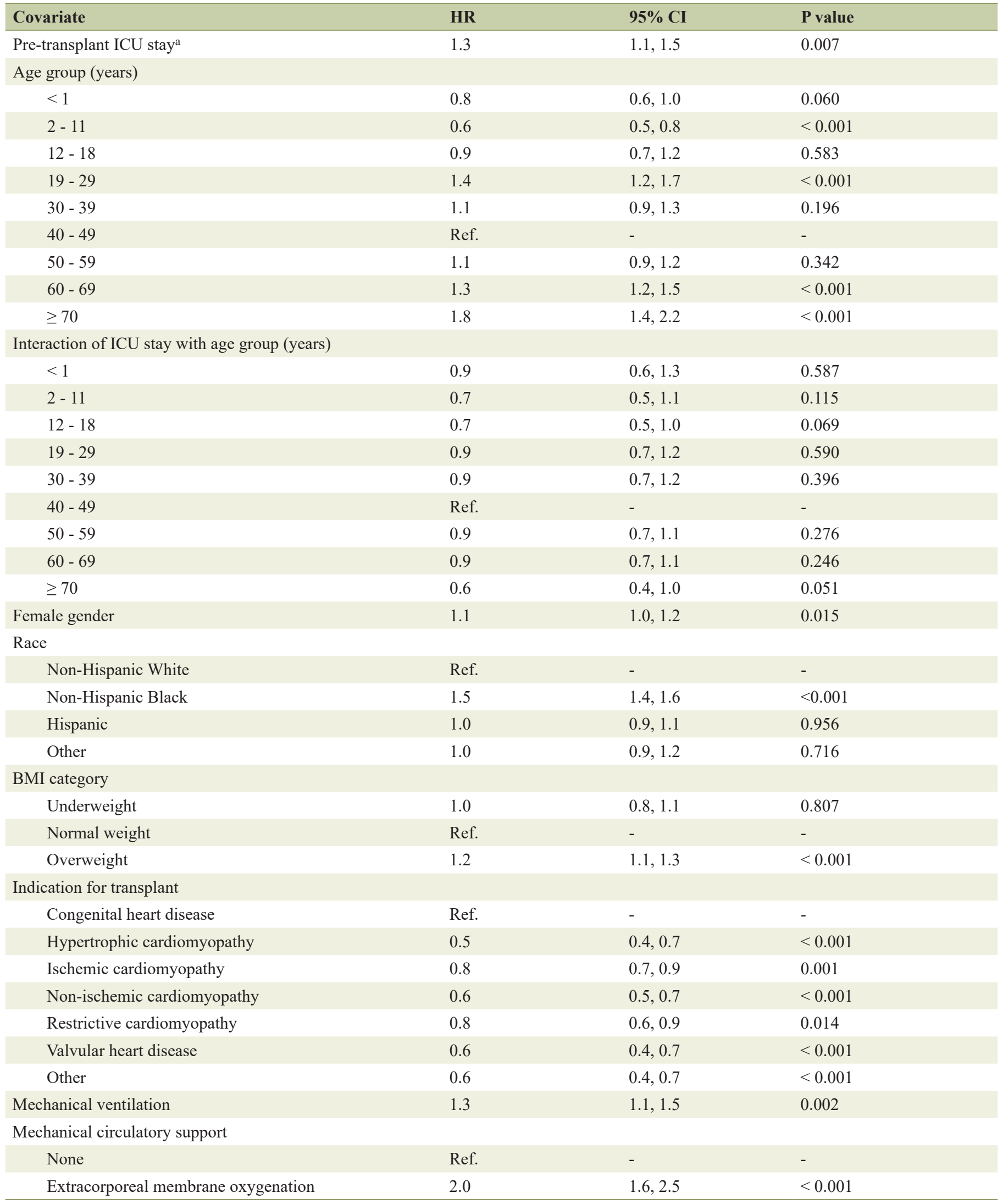


Table 3. Multivariable Cox Proportional Hazards Analysis of Overall Mortality After Heart Transplantation $(\mathrm{N}=18,396)$ - $($ continued)

\begin{tabular}{llll}
\hline Covariate & HR & 95\% CI & P value \\
\hline \multicolumn{1}{c}{ Ventricular assist device } & 1.1 & $1.0,1.2$ & 0.001 \\
Inotrope use & 1.0 & $0.9,1.1$ & 0.632 \\
Dialysis on waitlist & 1.8 & $1.5,2.2$ & $<0.001$ \\
Bilirubin $>$ 2 mg/dL & 1.2 & $1.1,1.3$ & $<0.001$ \\
Infection requiring IV antibiotics & 1.2 & $1.1,1.3$ & $<0.001$ \\
Allograft ischemia time (h) & & & - \\
$\quad<2$ & Ref. & 0.888 \\
$\quad 1.0$ & 1.2 & $0.9,1.1$ & $<0.001$ \\
\hline
\end{tabular}

aHazard ratio (HR) reflects estimate for ages 40 - 49 years. The interaction terms estimate how this HR is modified in other age groups. BMI: body mass index.

\section{Author Contributions}

TS drafted the manuscript and did revisions. DT shared the idea for the article and helped with data and data analysis. DH provided review and edits. JT did critical review and supervision.

\section{References}

1. Almond CS, Gauvreau K, Canter CE, Rajagopal SK, Piercey GE, Singh TP. A risk-prediction model for in-hospital mortality after heart transplantation in US children. Am J Transplant. 2012;12(5):1240-1248.

2. Hsieh A, Tumin D, McConnell PI, Galantowicz M, Tobias JD, Hayes D, Jr. Influence of transplant center procedural volume on survival outcomes of heart transplantation for children bridged with mechanical circulatory support. Pediatr Cardiol. 2017;38(2):280-288.

3. Rossano JW, Dipchand AI, Edwards LB, Goldfarb S, Kucheryavaya AY, Levvey Rn BJ, Lund LH, et al. The registry of the international society for heart and lung transplantation: nineteenth pediatric heart transplantation report-2016; Focus theme: primary diagnostic indications for transplant. J Heart Lung Transplant. 2016;35(10):1185-1195.

4. Lund LH, Edwards LB, Dipchand AI, Goldfarb S, Kucheryavaya AY, Levvey BJ, Meiser B, et al. The registry of the international society for heart and lung transplantation: thirty-third adult heart transplantation report-2016; focus theme: primary diagnostic indications for transplant. J Heart Lung Transplant. 2016;35(10):1158-1169.

5. Morrow WR, Frazier E, Naftel DC. Survival after listing for cardiac transplantation in children. Prog Pediatr Cardiol. 2000;11(2):99-105.

6. Davies RR, Russo MJ, Mital S, Martens TM, Sorabella RS, Hong KN, Gelijns AC, et al. Predicting survival among high-risk pediatric cardiac transplant recipients: an analysis of the United Network for Organ Sharing da- tabase. J Thorac Cardiovasc Surg. 2008;135(1):147-155, e141-142.

7. Allen JG, Weiss ES, Arnaoutakis GJ, Russell SD, Baumgartner WA, Conte JV, Shah AS. The impact of race on survival after heart transplantation: an analysis of more than 20,000 patients. Ann Thorac Surg. 2010;89(6):19561963; discussion 1963-1954.

8. Rana A, Fraser CD, Scully BB, Heinle JS, McKenzie ED, Dreyer WJ, Kueht M, et al. Inferior outcomes on the waiting list in low-volume pediatric heart transplant centers. Am J Transplant. 2017;17(6):1515-1524.

9. Mital S, Addonizio LJ, Lamour JM, Hsu DT. Outcome of children with end-stage congenital heart disease waiting for cardiac transplantation. J Heart Lung Transplant. 2003;22(2):147-153.

10. Hong KN, Iribarne A, Worku B, Takayama H, Gelijns AC, Naka Y, Jeevanandam V, et al. Who is the high-risk recipient? Predicting mortality after heart transplant using pretransplant donor and recipient risk factors. Ann Thorac Surg. 2011;92(2):520-527; discussion 527.

11. Taylor DO, Stehlik J, Edwards LB, Aurora P, Christie JD, Dobbels F, Kirk R, et al. Registry of the international society for heart and lung transplantation: twenty-sixth official adult heart transplant report-2009. J Heart Lung Transplant. 2009;28(10):1007-1022.

12. Colvin M, Smith JM, Skeans MA, Edwards LB, Callahan ER, Snyder JJ, Israni AK, et al. Heart. Am J Transplant. 2016;16(Suppl 2):115-140.

13. Wehman B, Stafford KA, Bittle GJ, Kon ZN, Evans CF, Rajagopal K, Pietris N, et al. Modern outcomes of mechanical circulatory support as a bridge to pediatric heart transplantation. Ann Thorac Surg. 2016;101(6):23212327.

14. Davies RR, Russo MJ, Hong KN, O'Byrne ML, Cork DP, Moskowitz AJ, Gelijns AC, et al. The use of mechanical circulatory support as a bridge to transplantation in pediatric patients: an analysis of the United Network for Organ Sharing database. J Thorac Cardiovasc Surg. 2008;135(2):421-427, e421. 